\title{
Histórias e narrativas de si: memórias de docentes que atuaram numa escola rural no norte do Rio Grande do Sul $(1964-1985)^{1}$
}

\section{Stories and narratives of you: memories of teachers that worked in a rural school in the north of Rio Grande do Sul (1964-1985)}

\author{
Darciel Pasinato* \\ Rosangela Fritsch*
}

\begin{abstract}
RESUMO
$\mathrm{O}$ artigo tem por objetivo analisar as memórias de docentes rurais, que atuaram na Escola Aníbal Magni, na comunidade de Arroio Grande, no pequeno município de Selbach, localizado no norte do Rio Grande do Sul, Brasil, entre 1964 e 1985, em plena Ditadura Civil-Militar. A pesquisa tem a Memória como pressuposto teórico e utiliza a metodologia da História Oral. A memória assume papel decisivo, visto que, além de ser um dispositivo da História, ela é, por primazia humana, uma propriedade de preservar certas informações. Para constituir este estudo, usando a entrevista como estratégica metodológica, ouvimos dez professores que ofereceram sua história de vida envolvendo-se tanto na temática foco, memórias docentes, como também naquilo que a envolve: o próprio existir. As memórias permitem uma visibilidade ao cotidiano escolar, seus espaços e tempos, visibilizando marcas das escolas rurais no contexto da Ditadura Civil-Militar. A proporção
\end{abstract}

1 Este artigo é fruto de uma pesquisa de Pós-doutorado, desenvolvida junto ao Programa de Pós-Graduação em Educação da Universidade do Vale do Rio dos Sinos (UNISINOS), financiado pelo Programa Nacional de Pós-Doutorado da Coordenação de Aperfeiçoamento de Pessoal de Nível Superior (PNPD/CAPES).

* Universidade do Vale do Rio dos Sinos. São Leopoldo, Rio Grande do Sul, Brasil. E-mail: darcielpasinato1986@gmail.com - https://orcid.org/0000-0003-4167-2025 E-mail: rosangelafritsch15@gmail.com - https://orcid.org/0000-0002-0630-3649 
mais colaborativa presente nas comunidades rurais é citada pelos docentes, representada pelas celebrações, festividades e relações sociais mais coletivas.

Palavras-chave: Memórias docentes. Escola rural. História Oral. Ditadura Civil-Militar.

\begin{abstract}
The article aims to analyze the memories of rural teachers who worked at Escola Aníbal Magni, in the community of Arroio Grande, in the small municipality of Selbach, located in the north of Rio Grande do Sul, Brazil, between 1964 and 1985, in the middle of the Dictatorship Civil-Military. The research has Memory as a theoretical assumption and uses the methodology of Oral History. Memory assumes a decisive role, since, in addition to being a device of history, it is, by human primacy, a property of preserving certain information. To constitute this study, using the interview as a methodological strategy, we listened to ten teachers who offered their life stories involving themselves both in the thematic focus, teaching memories, as well as in what involves it: the very existence. Memories allow visibility to the school's daily life, its spaces and times, showing marks of rural schools in the context of the Civil-Military Dictatorship. The most collaborative proportion present in rural communities is mentioned by the teachers, represented by the most collective celebrations, festivities and social relations.
\end{abstract}

Keywords: Teachers memories. Rural school. Oral History. Civil-Military Dictatorship.

\title{
Introdução
}

Os anos de 1960 e 1970, no Brasil, estabeleceram uma nova dinâmica em diversos setores, como político, social, econômico e educacional, em detrimento da Ditadura Civil-Militar instaurada nesse período. A Ditadura tinha como pretexto a abertura da normalidade econômica, a defesa do capitalismo e a segurança nacional contra o predomínio do pensamento comunista, especialmente pelos grupos conservadores.

Por recusar verdades definitivas e perceber que a História e as memórias se situam em áreas de divisa entre a verdade e a ficção, entre o real e não real, a pesquisa procura uma reformulação do passado, sob o aspecto da descontinuidade. Na elaboração das memórias opera-se uma espécie de imaginação controlada. Há uma predisposição dos historiadores em não estabelecerem qualquer diferença 
entre ficção e história. Todo o relato histórico é um discurso, assim como o mito e a literatura são formas de conhecimento (PESAVENTO, 2004). Qualquer forma de história necessita dos mecanismos de composição respectivos da narrativa, e que, desse modo, a ideia da história como pesquisa do passado é inerente ao relato deste passado sob forma de narrativa.

No entanto, é possível refletir que os relatos carregam algo sobre o período analisado (1964-1985). A chave para a análise reside em pegar cada depoimento em sua integralidade, descobrindo não só o que foi dito, como também o que não foi falado. A entrevista e as circunstâncias nas quais ela se deu adquirem um papel relevante neste caso. A pesquisa tem a Memória como pressuposto teórico e utiliza a metodologia da História Oral.

$\mathrm{O}$ artigo tem por objetivo analisar as memórias de docentes rurais, que atuaram na Escola Aníbal Magni, na comunidade de Arroio Grande, no pequeno município de Selbach, localizado no norte do Rio Grande do Sul, Brasil, entre 1964 e 1985, em plena Ditadura Civil-Militar. O artigo, além da introdução e das considerações finais, divide-se em quatro partes. Na primeira parte, analisamos o percurso teórico e metodológico das fontes orais. Na segunda parte, examinamos a trajetória das escolas rurais no Brasil. Na terceira parte, estudamos a história da comunidade de Arroio Grande e a Escola Aníbal Magni. Na quarta parte, analisamos as memórias dos docentes rurais.

\section{Percurso teórico e metodológico das fontes orais}

A opção teórica é pela História Cultural, identificando-se como uma abordagem para se analisar a ciência histórica pensando a cultura como "[...] um conjunto de significados partilhados e construídos pelos homens para explicar o mundo" (PESAVENTO, 2004, p. 15). Nesta pesquisa, compreende-se como História o campo de produção do conhecimento que se alimenta de teorias explicativas e de fontes que corroboram para o entendimento das diferentes ações humanas no tempo e no espaço.

A História é fadada pelos feitos dos homens no tempo, uma vez que não é apenas a essência humana quem comanda os seus feitos, mas também sua temporalidade. Do mesmo modo nos remetemos à História da Educação, "[...] que tem como seu objeto de pesquisa, o fenômeno educativo, mas não somente ele, antes desdobra os olhares para os sujeitos e os locais onde este fenômeno está inserido" (IVASHITA; DOMINGUES, 2018, p. 21). Para percebermos tal fenômeno, é necessário que analisemos as fontes de pesquisa que a História da Educação nos propõe. 
Werle (2004) examina o tempo como dimensão que se manifesta tanto nos espaços subjetivos como objetivos, ele está colocado em espaços da vida institucional, grupal ou individual. Dessa forma, tratando-se da memória, é de suma relevância entendê-la como razão essencial no trabalho de reconstituição da vida escolar, porque os relatos, as narrativas e os pensamentos disponibilizam ao pesquisador diferentes aproximações sobre as relações que se travaram para a constituição da instituição.

A memória, não sendo a História, é vista como uma construção social que decorre do relacionamento, posição e papéis sociais do sujeito com o mundo da vida. A lembrança é coletiva, e nessa memória o indivíduo tem uma concepção individual dos fatos vividos, contudo, ela se dá pelo contato entre os membros da comunidade e as trajetórias vivenciadas entre eles (HALBWACHS, 2006).

Amado (1995) ressalta que toda a narrativa alcança certa fabulação, uma criação da realidade vivida, mesmo que detenha uma dimensão simbólica que movimenta um certo desinteresse do real em busca do imaginário, então, antes de mais nada, um entendimento sobre algo. Da mesma forma, o relato não é algo absoluto, imóvel, contudo resulta muito de elementos articulados, por exemplo: "[...] quem narra, o que narra, como narra, para quem narra, quando narra" (AMADO, 1995, p. 133).

A História estruturada em bases tradicionais não percebe a lembrança como um documento histórico transparente "[...] por considerar a possibilidade de distorção dos fatos, uma vez que os narradores são sujeitos mais velhos que comumente acentuam um tom nostálgico às suas lembranças" (ALMEIDA, 2009b, p. 214). De outra forma, Thomson (1997) critica essa visão de História, alegando que a eliminação das fantasias, que são específicas de sua construção, dificulta o processo de afloramento das lembranças e não aprova a exploração dos significados subjetivos das práticas vividas pelos indivíduos e por coletividades.

É por intermédio da narrativa que os sujeitos individuais e sociais mergulham em suas histórias, na procura da elaboração de identidades individuais e coletivas. Os espaços da memória, então, podem ser considerados suportes da identidade social, construções que têm, deste modo, a função de impedir que o presente se altere em um processo contínuo, separado do passado e livre com o futuro. O mesmo se pode falar da metodologia da História Oral, que, sendo uma produção intelectual conduzida para a produção de depoimentos históricos, colabora para afastar o esquecimento e para mostrar diversos olhares sobre o que passou. Além de colaborar para a construção/reconstrução da identidade histórica, "[...] a História Oral empreende um esforço voltado para possibilitar o afloramento da pluralidade de visões inerentes à vida coletiva" (NEVES, 2000, p. 112). 
Fischer (1997) propõe uma proximidade entre as pesquisas que trabalham com recordações e com a metodologia da História Oral. O entendimento dos depoimentos dos narradores não procura um conhecimento verdadeiro, mas um reconhecimento das condições de possibilidade para que determinada narrativa surja enquanto discurso. As narrativas de memória, da mesma maneira, são práticas discursivas.

Adotamos a concepção da História Oral, aqui entendida como acesso à memória, ou seja, a anotação de uma ação individual ou coletiva, à recordação de um tempo que não pode ser esquecido, que proporciona não somente o encontro com o passado, mas, especialmente, na reestruturação e reflexão do vivido. Como assinala Le Goff (2013, p. 387), "[...] a memória tem a propriedade de conservar certas informações, remete-nos em primeiro lugar a um conjunto de funções psíquicas, graças às quais o homem pode atualizar impressões ou informações passadas". Essa renovação beneficia aspectos que concretizam as lembranças, como sentidos, biológicos e psicológicos, os locais e o tempo. No que diz respeito a isso, Nora (1993) intitula de lugares de memória, na qual demonstra que o homem tem a necessidade de determinar lugares e objetos como repositórios de recordação.

É evidente para os sujeitos da pesquisa que o investigador está ali produzindo, por meio da entrevista, um documento histórico. O pesquisador conduz neste processo como intermediário, entre o contato, o ofertado pelo narrador, relacionando todas essas informações e usando a História Oral como método, enaltecendo as narrativas orais ao status de documento escrito. Nas palavras de Meihy e Holanda (2010), a História Oral, enquanto procedimento, provoca mediação na qual o investigador age como intermediário, agente de ações realizadas por outros.

O grupo social é composto por dez sujeitos, que foram docentes da Escola Municipal de Ensino Fundamental Aníbal Magni, que representam o conjunto de memórias, que estão elaboradas a partir das narrativas coletadas ao longo do estudo realizado no ano de 2019. Utilizamos nomes fictícios para preservar a identidade e não expor a opinião de nenhum professor. Destacase que a média de idade dos docentes é de 72 anos e a média do período que atuaram como professor na Escola é de 11 anos.

Nesta pesquisa, evidenciou-se o debate do uso das memórias narrativas como concepção investigativa para o estudo da História da Educação, tendo como pressupostos as fontes orais. As memórias autobiográficas permitem entender e perceber como a cultura escolar foi se estabelecendo no interior da Escola Municipal Aníbal Magni. Optou-se pela entrevista valendo-se da metodologia da História Oral. Usando-se desta modalidade, definiu-se um 
roteiro com questões com foco nas memórias de docentes da Escola Aníbal Magni na Ditadura Civil-Militar, entre 1964 e 1985. Pretende-se explorar as seguintes categorias de análise: a) trajetória docente na escola rural; b) relação aluno, professor e comunidade escolar; c) repercussões da Ditadura Civil-Militar brasileira em sala de aula.

A entrevista foi usada como recurso para a narrativa, porque "[...] são as que versam sobre a participação do entrevistado no tema escolhido" (ALBERTI, 2005, p. 175). Ao escutar, considerou-se a questão do tempo e das opiniões. No decorrer da idade e da exaustão, a memória fica limitada, sendo preciso retomar o fôlego para avançar. Os depoimentos caracterizam um modo de refletir, ser e agir de indivíduos, advindo de associações entre a narrativa e a criação. Oportunidades em que a imaginação estava muito presente no discurso do entrevistado, por se instituir nas representações que fez do meio escolar.

A entrevista admite que possa manifestar especificidades tanto tocantes às histórias de vida dos narradores, bem como as entrecruzadas no contexto situacional. Melhor dizendo, na conversa foi possível incentivar e encorajar os informantes narradores a conectarem sua história de vida, no caso as memórias de docentes na Escola Aníbal Magni, no período da Ditadura Civil-Militar (1964-1985) com acontecimentos considerados relevantes, no contexto social em que sobreviveram (JOVCHELOVITCH; BAUER, 2002).

Cabe destacar que há neste tipo de estudo o princípio da cooperação que associa o narrador do ouvinte, cujas histórias surgem mediante a comunicação, a troca, a conversa entre o entrevistador e seus colaboradores (CRESWELL, 2007). Sendo ouvinte, investigador e escritor responsável por reconstruir o narrado, há de compreender que seu comprometimento provoca posição de participação revelada em face da vida e dos problemas ali narrados. Desta maneira, a pesquisa narrativa transforma-se em metodologia fundamental para a concepção da noção de coletividade.

Trabalhar com as proporções da memória oral é estar consciente do rigor metodológico analítico dos enunciados, que às vezes se entrecruzam com lembranças de outros lugares e tempos, dispersando do que se pretende reunir de informações sobre o objeto em investigação. Desta forma, a entrevista com o roteiro dos temas a serem examinados foi indispensável. O propósito era guiar a entrevista, sem deixar o entrevistado preso a uma sucessão de questionamentos.

Após a transcrição, foi levada ao entrevistado para leitura e ajustes necessários, levando em consideração as posições e as sugestões consolidadas no produto final. Grazziotin e Almeida (2012, p. 40) chamam a atenção para o fato de que o pesquisador " [...] transcrever pessoalmente todas as entrevistas nos parece uma decisão acertada, pois, ao transcrever, é possível lembrar dos aspectos marcantes do encontro e fazer anotações paralelas às falas". Seguindo 
o que determina o Comitê de Ética em Pesquisa da UNISINOS, os entrevistados assinaram o Termo de Consentimento Livre e Esclarecido (TCLE).

\section{Trajetória das escolas rurais no Brasil}

Na década de 1920, quando o Brasil passava por grandes mudanças políticas e econômicas, surge o movimento educacional intitulado ruralismo pedagógico (1927), que tinha como justificativa básica a ideia de fixação do homem no campo através da pedagogia. As primeiras políticas públicas para o ensino primário rural remontam da segunda década do século $\mathrm{XX}$, todavia foi no final da década de 1940 que se expandiram projetos educacionais exclusivos para a escola primária rural. Para Moraes (2014), anteriormente o que distinguia a escola primária rural de outras escolas primárias era a questão da localização geográfica.

Como salienta Bezerra Neto (2003), na primeira metade do século XX ocorre certa luta em defesa de um projeto de nacionalização, que se dava também por intermédio da proteção da educação e da escola pública. Seus signatários admitiam que a permanência dos trabalhadores em áreas rurais permitiria preservar integralmente a nação. Em outra observação Nagle (1974) informa que a ideologia ruralista era

[...] o elemento anti-industrialista, empregando recursos para manter a predominância do universo agrário-comercial. O ruralismo representava um ponto de vista anti-urbano. Fundamentando-se na exaltação das vantagens naturais da vida rural, difunde uma atitude pessimista, que encobre interesses contrariados pelo meio citadino. Este é acusado de artificial, destruídos da solidariedade natural do homem. Por isso, o urbanismo é tido como um processo de degeneração e desintegração social; com ele se inicia o declínio da civilização (NAGLE, 1974, p. 26).

A educação defendida pelos ruralistas não se definia apenas ao ensino geral, contudo, especialmente a educação agrícola que, naquele período, em que o campo estava progredindo, implicava na necessidade de uma maior formação dos trabalhadores para esse setor. Bezerra Neto (2003) ressalta que até a década de 1930, a escola era vista como irrelevante e desnecessária para o homem do campo, já que a forma como a agricultura e pecuária eram praticadas (com técnicas obsoletas) não requisitava nenhum aprendizado especial. 
Além da indiferença pelo trabalho do docente, havia uma grande diferença entre o salário do professor rural e urbano. Remunerava-se melhor o docente urbano, visto que seu trabalho era tido como mais difícil, enquanto o do professor rural era mais fácil "[...] porque parte do que ensinavam aos alunos era de conhecimento de todos ou então, o professor ensinava apenas a ler e escrever" (MACHADO, 2016, p. 79).

Nos anos de 1950, o discurso higienista encontrava-se presente nas atividades voltadas para a educação dos alunos das escolas rurais, e este deslocou a concepção de ensino voltado para as questões raciais pela educação do povo simples, "[...] em meio a discussões que também problematizavam a oposição entre campo e cidade e a necessidade de sua superação, seja pelo planejamento econômico, seja pela educação" (VEIGA, 2007, p. 266).

Com a constituição do Fundo Nacional do Ensino Primário em 1942 pelo governo federal, através do Decreto n. 4.958 (BRASIL, 1942), que tratava das determinações para a escola rural, foi definida a ajuda financeira da união com os estados, através da autorização de auxílio financeiro e amparo técnico para o ensino primário. Os estados precisariam investir pelo menos $15 \%$ de sua receita e os municípios 10\%. De acordo com Carvalho e Castro (2014, p. 15), "“...] a descentralização dos recursos foi acompanhada também pela descentralização das responsabilidades administrativas e pedagógicas". Os estados continuam responsáveis pelo ensino primário nas áreas urbanas e os municípios com as zonas rurais.

Em 1949, o Instituto Nacional de Estudos Pedagógicos (INEP) divulgou o cuidado com a vontade de aperfeiçoamento da educação rural no país, evidenciando os grandes problemas presentes neste meio como o transporte, a habitação, os recursos de educação e condições gerais de trabalho. As conclusões apresentadas pelo INEP apontam que a educação rural é vista como "[...] um instrumento capaz de formar, de modelar um cidadão adaptado ao seu meio de origem, mas lapidado pelos conhecimentos científicos endossados pelo meio urbano" (ALMEIDA, 2009a, p. 287).

Demartini (1998) ao analisar a educação rural nos anos de 1960, compreendeu que os processos de industrialização, urbanização, além das transformações nos processos produtivos no meio rural, passaram a requisitar novos conhecimentos através do trabalhador, entre eles: leitura, escrita e cálculo - ainda que de maneira rudimentar. De fato, as populações rurais passaram a apreciar ainda mais a escola e a acessá-la.

Na década de 1970, a Lei de Diretrizes e Bases da Educação Nacional (LDB), Lei n. 5.692/71 (BRASIL, 1971), previa em seu Artigo 11 que, no espaço rural, o estabelecimento poderia estruturar os períodos letivos, com indicação de férias nos períodos do plantio e colheita de safras, de acordo com plano aprovado pela autoridade de ensino. O Programa de Expansão e Melhoria do 
Ensino Rural (EDURURAL), desenvolvido nos estados do Nordeste, procurou disponibilizar subsídios para acompanhamento da qualidade da escolarização oferecida às crianças através dos conteúdos escolares, “[...] dos recursos materiais e didáticos, do preparo do professor e de suas condições de trabalho, da estrutura e funcionamento da escola" (BARRETO, 1983, p. 23).

Em 1982, o governo federal, no III Plano Setorial de Educação, Cultura e Desporto 1980-1985 (PSECD), identificou como linha programática a educação no meio rural, por ser esta

[...] o foco mais acentuado de pobreza no país e apresentar as menores taxas de escolarização, os maiores índices de repetência e evasão e a maior dificuldade de adequação da educação às particularidades da clientela $\mathrm{e}$ do meio (MACHADO, 2016, p. 84).

Ao tratar as estratégias peculiares para as regiões do Brasil, o III PSECD evidencia para a região Sudeste o avanço da qualidade do ensino de $1^{\circ}$ grau, de acordo com as alternativas de educação não-formal, com apoio às experiências comunitárias e a uma supervisão educacional mais eficaz. Para as regiões Norte, Nordeste e Centro-Oeste, os métodos referem-se principalmente ao crescimento das oportunidades educacionais, pela oferta das quatro séries do $1^{\circ}$ grau tanto para as crianças como para os adultos. Para o Sul, as estratégias não estavam voltadas para a ampliação das oportunidades educacionais, mas sim para a excelência do ensino.

\section{A história da comunidade de Arroio Grande e a Escola Aníbal Magni}

O município de Selbach, onde fica a comunidade de Arroio Grande, está localizado no norte do Rio Grande do Sul, Brasil, e possui aproximadamente cinco mil habitantes. Selbach ${ }^{2}$ foi um caso de latifúndio improdutivo, cujas terras

2 Até 1924, Selbach pertenceu ao Distrito de Passo Fundo. Em 1931, Selbach passou a ser o quarto Distrito de Carazinho. Em 1954, Tapera se desmembrou de Carazinho e Selbach passou a ser o segundo Distrito de Tapera. Com a Lei Estadual n. 4.762 de 30 de julho de 1964 (RIO GRANDE DO SUL, 1964), a Assembleia Legislativa do Rio Grande do Sul ofereceu a oportunidade para a criação de novos municípios. Dessa maneira, formou-se a Comissão Emancipacionista de Selbach, para pleitear sua independência política, econômica e social. No dia 22 de setembro de 1965 foi criado o município de Selbach. Em 13 de maio de 1966 foi instalado o município e nomeado como interventor federal Beno Ely, pelo fato do Brasil estar sob uma Ditadura Civil-Militar. 
foram vendidas por estancieiros a companhias colonizadoras ou a particulares. Boa parte destas terras foi adquirida pelo Coronel Jacob Selbach Júnior em 1887, do Governo Federal, iniciando-se um núcleo inicial de colonização apenas em 1905. O início do povoamento de Selbach se deu com a chegada dos alemães, dos municípios de São Leopoldo, Venâncio Aires, Santa Cruz do Sul, Montenegro e São Sebastião do Caí.

Por volta de 1910, vieram os primeiros colonizadores da comunidade de Arroio Grande de municípios como São Leopoldo, Anta Gorda, Santa Cruz do Sul, Cachoeira do Sul, em busca de terras produtivas. A fertilidade do solo e o preço baixo dessas terras vinham ao encontro desses colonos, pois tinham como objetivo "[...] povoar e produzir, como um novo lar e uma propriedade, própria para suas famílias" (WEBER; HOLZ, 1999, p. 25).

De posse de suas terras, os colonos sentiram a necessidade de notificar as suas famílias deixadas em sua terra natal e propagar a riqueza dos pinhais e a fertilidade da terra nova. Os colonos dedicavam-se à agricultura, buscando sua sobrevivência e seu desenvolvimento econômico. As vestimentas eram trazidas em quantidade suficiente, pois não havia vendas onde pudessem comprar tecidos para confecções de roupas (WEBER; HOLZ, 1999).

Em 1920, um novo grupo de colonos chegou à comunidade de Arroio Grande. Com isso, cresceram o número de famílias e foram aparecendo as primeiras bodegas, moinhos, ferrarias, serrarias, olarias, igrejas e escolas. A floresta era formada por pinheiros, que eram devastados para prática da agricultura de subsistência. Entre 1930 e 1940, com o preço elevado da madeira, "[...] foi estimulado a instalação de várias serrarias, com isso a madeira tornou-se fonte de renda muito importante" (WEBER; HOLZ, 1999, p. 30).

Com o crescimento da população e, consequentemente, com o número de crianças em idade para frequentar a escola, os colonos incentivaram o início da atividade escolar. Em 1922 começa a funcionar a primeira escola na Igreja Luterana. No início à escola era confessional/privada, mantida pela comunidade religiosa. As turmas eram multisseriadas, os professores ensinavam basicamente a leitura, a escrita e a matemática básica (cálculos). As aulas eram ministradas pelo professor Arthur Apel, que era pago pelos pais dos alunos (FINGER et al., 1996).

A partir da década de 1950, a escola torna-se pública, gratuita e laica, e, consequentemente, o número de estudantes aumenta e era necessário um espaço físico maior e adequado. Isso acaba favorecendo, que em 1956, por iniciativa de alguns pais de alunos e para melhorar o atendimento às crianças, foi adquirida uma área de terra através de Adolfo Albino Werlang e Oscar Henrich. É relevante destacar que boa parte da comunidade colaborou na compra dessa terra (SCHNEIDER; WENTZ, 1992). 
Em 1961, a Escola Aníbal Magni foi construída e funcionou até 1974, quando foi destruída por um forte temporal. Com poucos recursos e com o aumento dos alunos devido ao crescimento da comunidade, o terreno foi cedido ao Estado na década de 1970, sendo construída uma escola de alvenaria. Com o fechamento das escolas de outras comunidades devido ao reduzido número de alunos, e visando um melhor atendimento, os discentes destas escolas passaram a frequentar a Escola Municipal de Ensino Fundamental Aníbal Magni, que se transformou numa escola polo.

\section{Memórias de docentes rurais}

A partir do início do regime republicano (1889), aconteceu o crescimento do ensino público com a implementação de escolas elementares na região urbana, entretanto, o mesmo não ocorreu no meio rural. A zona rural estava servida de escolas comunitárias, que eram sustentadas por associações, teoricamente ligadas à Igreja Católica ou Luterana, dependendo da comunidade (WERLE, 2010). Nessa perspectiva, Rambo (1994) salienta, a partir de estudos na região de imigração alemã, antes mesmo de cogitar em erguer uma igreja, os alemães tratavam de construir uma escola.

A educação rural, até meados do século XX, foi vista como um instrumento capaz de constituir, de formar um cidadão apropriado ao seu meio de origem, contudo aprimorado pelos conhecimentos científicos transmitidos pelo meio urbano. Sob influência europeia, no início do século XIX, os imigrantes alemães criaram as primeiras escolas na região que hoje corresponde ao município de São Leopoldo, no Rio Grande do Sul. A tríade, Igreja, Escola e Cemitério, é aspecto que representava o cenário das comunidades germânicas situadas em diferentes partes do Brasil (ARENDT, 2008). Os caminhos abertos pelos imigrantes originaram lugares, isso aconteceu em Selbach e na comunidade de Arroio Grande. Arendt (2008) reconhece esta forma de escola como Kolonieschulen (escolas rurais).

A discussão sobre uma educação capaz de firmar o homem no campo e conservar a cultura nacional foi motivada pelo medo do êxodo rural - referente à busca de melhores oportunidades de trabalho nos centros urbanos - e de suas decorrências: a deslocação da produção no campo e o inchaço das cidades, o que levaria problemas sociais graves. Estas foram as essenciais defesas do movimento denominado de Ruralismo Pedagógico, especialmente nos anos de 1940 e 1950 (DEMARCO, 2001). 
O movimento de defesa da educação rural possuía como objetivo central a proteção da cultura nacional em oposição à cultura urbana e política dos imigrantes europeus e os modelos de desenvolvimento econômico vindos do exterior. O que os ruralistas não evidenciavam é que sem a solução paralela dos problemas de saúde, de nutrição, de conhecimento técnico, a educação ficaria incapaz de sozinha assegurar a fixação do homem no campo e aprimorar suas condições de vida. Nas palavras de Martins (2015, p. 75), “[...] muitas críticas foram tecidas ao Ruralismo Pedagógico, por ser um conjunto de ideias pedagógicas que visam à manutenção do camponês na terra através da educação".

Apesar do papel pertinente que desempenharam na escolarização de uma parte considerável da população brasileira, as instituições rurais de ensino ficaram, durante muito tempo, preteridas ao esquecimento. O afã de modernização que se instalou no final dos anos de 1950 e, por conseguinte, relacionou o passado com o atraso e com o mundo rural, ter-se-ia estabelecido em um dos fatores a proporcionar o silêncio ao redor desta modalidade de escola (SILVEIRA, 2010).

Após cinco décadas da instauração da Ditadura Civil-Militar, em 1964, a memória do período apresenta uma faceta negativa, quer dizer, ninguém quer se vincular ao período. A escola não ficou imune a todas essas transformações. As principais reformas decorreram após a promulgação da Lei n. 5.692/71 (BRASIL, 1971) e acarretaram "[...] a unificação do ensino primário, de $1^{\mathrm{a}}$ à $4^{\text {a }}$ série, com o ensino ginasial, eliminando-se o exame de admissão, que selecionava os ingressantes para a segunda fase" (LOURENÇO, 2010, p. 98). A partir de então, criou-se o ensino de $1^{\circ}$ grau, com 8 séries, com função profissionalizante nos locais onde os alunos finalizassem sua vida escolar nesse nível. Onde houve condições de extensão dos estudos até o $2^{\circ}$ grau, este teria a missão da profissionalização.

A professora Júlia lembra de vários fatos que marcaram a sua trajetória como docente da Escola Aníbal Magni, como relata a seguir:

Passei por momentos dificeis. Épocas que fui perseguida na Escola e tinha que cuidar muito o que falava. Com os alunos me dava bem. Era dificil ser professora, porque não tinha recurso, não tinha internet para pesquisar. Outro fato que me marcou foi que deu um temporal e demoliu a Escola em 1974. Ai trabalhamos no pavilhão da comunidade por um periodo. Depois o Estado construiu uma escola de material. Muitos documentos foram perdidos por causa desse temporal (Júlia). 
Chama a atenção a questão da falta de recursos materiais para ser docente, conforme a professora relatou no excerto. As escolas rurais eram precárias, com poucos docentes e as classes eram multisseriadas, geralmente cada professor atendia duas a três turmas ao mesmo tempo. No que diz respeito à trajetória como docente, a professora Isabel relata que procurava ter uma boa relação com os alunos.

Na quinta série tinha os malandros. A gente saia para fazer piqueniques com os alunos. Nas festas da comunidade de Arroio Grande, as crianças procuravam a professora. Um fato negativo que recordo foi que, pelo desentendimento, tive que sair da Escola Anibal Magni e fui para outra escola do interior de Selbach. Quando me transferiram tirei um ano de licença interesse sem remuneração. Na verdade era perseguição política (Isabel).

É relevante destacar, a partir das narrativas, que muitos professores foram perseguidos pela Ditadura Civil-Militar, principalmente quem atuava no ensino superior. No caso das escolas rurais, os docentes eram transferidos para outras escolas, muitas vezes pela questão político-partidária e também porque as comunidades do interior solicitavam a troca deles. A professora Rosane recorda que, quando chegou na Escola Aníbal Magni em 1978, a instituição não tinha nenhum material didático.

Comecei a dar aula numa quinta série que nem livro tinha. As crianças queriam aprender. Lembro que em História e Geografia fiz um projeto sobre o Rio Arroio Grande. Os alunos aprenderam a fazer redação. Em 1979 peguei o primeiro ano e as crianças eram esforçadas. Não tinham material didático e desenvolvi um projeto de leitura e criei uma cartilha. A Escola era atrasada e o professor usava apenas o quadro e os cadernos dos alunos para ensinar os conteúdos. Recordo que em 1979 teve a greve geral dos professores e mesmo assim continuei trabalhando (Rosane).

Em 1979 houve a greve geral dos docentes, que foi um movimento para contestar as políticas educacionais adotadas pela Ditadura e, acima de tudo, lutar por melhores condições de trabalho e salário digno para a categoria, além de defender a democracia através da eleição do Presidente da República. A professora Alice ressalta que, quando começou a dar aula na Escola Aníbal Magni, era muito jovem e não possuía formação adequada e experiência. 
Em primeiro lugar não tinha o curso de didática e tive que interagir com os alunos. Lembro que tinha um aluno teimoso que não gostava de fazer as atividades propostas. Os alunos queriam saber sobre a minha vida. Com o tempo fui interagindo, correndo atrás e pegando o jeito com os alunos. $O$ diretor era o Sérgio e era uma pessoa exigente. Também tinha merendeira e secretária na Escola. Fui bem acolhida por todos os professores da Escola Aníbal Magni (Alice).

A questão da falta de experiência para atuar nas escolas rurais era comum no período de 1960 a 1980, porque os professores começavam a dar aula com dezoito anos, em vários casos apenas com o Magistério. Em relação a sua trajetória como docente, a professora Lourdes destaca que foram muitos fatos positivos.

Gostei muito de trabalhar na Escola Aníbal Magni. O diretor Sérgio e sua esposa [merendeira] me acolheram como uma filha. O diretor colocava limite nos alunos. Quando era Dia das Crianças era feito um grande piquenique no campo do Cacique [comunidade de Arroio Grande] $e$ se transformava numa festa da comunidade. A maior dificuldade era o transporte escolar da Prefeitura de Selbach. Uma semana era um trajeto e outra tinha outra rota. No verão vinha de a pé com uma colega até a cidade. No inverno era ruim por causa do frio e da chuva. Tinha em média quinze alunos por turma, por isso era tranquilo. Podia atender bem o aluno. Sentia a valorização da escola por parte da comunidade (Lourdes).

Observamos no relato de duas docentes que ambas foram perseguidas na Escola Aníbal Magni pela questão política. É importante salientar que era o período da Ditadura Civil-Militar, onde não existia qualquer tipo de liberdade de expressão. Outros docentes falam que a Escola não possuía materiais didáticos e era o próprio professor que precisava criá-los. Uma questão que aparece nas memórias era o piquenique, que geralmente acontecia no Dia do Estudante, onde toda a comunidade escolar procurava se envolver. Além disso, em 1974, um temporal destruiu a Escola e diversos documentos se perderam, certamente boa parte da história da própria instituição.

Nesse sentido, Errante (2000) destaca que o aspecto mais comum da memória são as recordações que são carregadas em detalhes, mais isso “[...] não implica a negação de outras formas de memória, que se traduzem nos silêncios, nos esquecimentos, nas rupturas na fala, nos gestos, nos olhares" (ERRANTE, 2000, p. 147). A lembrança é uma teia de tendências, por mais que haja imersão 
que se desafie o narrador, que se afaste a superficialidade durante a entrevista, não há como alcançar a totalidade daquilo que foi vivido no passado. Desse modo, a memória fundamenta-se dos atos de recordar e de ocultar, a um só tempo, e estes são produzidos socialmente. Como explica Bosi (2003, p. 18), "[...] cabe-nos interpretar tanto a lembrança quanto o esquecimento".

A professora Bernadete fala sobre a sua relação com os seus alunos e como a comunidade via a sua atuação como docente na Escola Aníbal Magni.

No meu ponto de vista, era melhor do que hoje em dia, a relação entre os professores e alunos no final da minha carreira como professora. Na vila de Arroio Grande tinha preconceito, o racismo era presente naquele periodo [década de 1980]. Os alunos que viviam na vila eram mais dificeis de lidar. Os pais não se envolviam nas atividades pelo fato de ser uma professora da cidade. Até hoje mantenho uma boa relação com os professores da Escola. Penso que a comunidade não lembra de mim (Bernadete).

O preconceito e o racismo marcam a narrativa e ainda está muito presente na sociedade brasileira na atualidade. Muitas pessoas ainda são vítimas, mesmo a legislação tendo avançado. Muitos aspectos precisam ser melhorados para combater o racismo. A professora Dolores lembra no seu relato que havia mais respeito entre os docentes e os alunos e os pais valorizavam a escola e o professor.

A professora de primeira série marca a vida dos alunos, pelo fato de ensinar a ler e escrever. Os alunos pequenos têm o lado do carinho. Com os alunos grandes parecia que não agradava. Com os pais a relação sempre foi tranquila. Não tinha situações de indisciplina. Não tinha necessidade de chamar os pais na Escola. Era muito bom dar aula para os alunos pequenos [primeira série]. As turmas eram pequenas e dava conta de atender a todos (Dolores).

Os pais costumavam se fazer presente nas atividades que a Escola Aníbal Magni organizava. A participação das comunidades rurais ainda é forte nos dias atuais nas escolas do campo. Os professores são mais valorizados pela comunidade escolar do que nas escolas urbanas. Sobre a relação entre professor e alunos e a comunidade escolar, o professor Rui recorda que tinha uma boa relação com seus colegas docentes e com seus alunos. 
A comunidade gostava do professor que vinha da cidade, porque iria dar conta das matérias. Os alunos respeitavam muito os professores. Geralmente, os alunos obedeciam e faziam o que era proposto. Em Arroio Grande, os alunos se destacaram mais tarde no Ginásio. Eram amigos fora da sala dos professores. Vinham conversar com o professor (Rui).

O professor Rui lembra que a comunidade valorizava muito o docente da cidade, nos anos de 1970, assim como os alunos procuravam realizar as atividades propostas em sala de aula. A professora Isabel relata que o professor era bem-visto, tanto pelos alunos como pela comunidade escolar.

Tinha uma relação muito boa e sempre me dei bem com os alunos. Os pais eram muito presentes na Escola. Ajudavam na limpeza do pátio, faziam as fogueiras de São João e faziam doações para a Escola [alimentos e dinheiro]. No começo [início dos anos 1970], não tinha transporte escolar. A maioria dos alunos era da comunidade de Arroio Grande. Depois que fecharam as outras escolas do interior de Selbach [década de 1980], muitos alunos vieram para a Escola Anibal Magni, e daí já tinha transporte para todos os alunos que vinham de outras comunidades (Isabel).

É relevante destacar que o apoio dos pais foi fundamental em muitas escolas rurais. Além de valorizar os docentes e a equipe diretiva, os pais participavam dos eventos realizados nas instituições de educação básica e contribuíam financeiramente para as escolas não fecharem. A professora Rosane salienta a lembrança de que o professor era mais valorizado e respeitado.

Lembro que os professores normalmente também eram catequistas na comunidade de Arroio Grande. A família era integrada na Escola. A Anibal Magni foi uma das melhores escolas que trabalhei na minha vida. Nunca precisei reclamar de falta de respeito da parte dos alunos. As crianças gostavam de trazer coisas para a professora, como bergamota e salame. Os alunos esperavam no ponto do ônibus para ir junto com a professora até a Escola (Rosane). 
De modo geral, os docentes possuíam uma boa relação com a comunidade escolar. Em um dos depoimentos, aparece que a Escola Municipal de Ensino Fundamental Aníbal Magni passa a receber mais alunos, a partir do início dos anos 1980, com o fechamento de outras escolas rurais no município de Selbach. Foi o período de nucleação das escolas rurais, ocorrido pela falta de alunos e docentes e pela infraestrutura precária. Sendo assim, muitas escolas deixaram de existir.

Lovisolo (1989) ressalta que as questões de memória têm a ver com nossos pertencimentos, com aquilo que idealizamos sobre nós mesmos, com nossas vontades, que vamos produzindo, desconstruindo e recompondo ao longo da vida. Do mesmo modo, Fentress e Wickham (1992, p. 39), afirmam que "[...] a nossa experiência do presente fica, portanto, inscrita na experiência passada". A lembrança simboliza o passado e o presente conectados entre si e coerentes, nessa lógica, um com o outro.

Em relação as repercussões da Ditadura Civil-Militar brasileira, o professor Sérgio lembra que não se falava de política em sala de aula.

O estudo era normal, o professor ensinava quem era o presidente da República. Entre os professores se falava pouco de política, porque não tinha tanta coisa ruim como hoje. Se fazia intercâmbio com as escolas para arrecadar dinheiro para comprar os materiais básicos. As escolas se apresentavam nas datas comemorativas com cantos e poesias. Outro intercâmbio era feito de futebol. A piazada ia de caminhão. Também gostava de futebol (Sérgio).

A Ditadura Civil-Militar procura valorizar a Educação Física, pois na visão dos militares queriam transformar o Brasil numa potência esportiva, através do futebol para estimular outros esportes. O objetivo era desviar as atenções do movimento estudantil para os problemas que o país enfrentava na política, na economia, na educação, entre outros. A professora Aparecida recorda que a Ditadura era trabalhada dentro da Escola através da Educação Moral e Cívica.

Me despertou o lado da Ditadura quando fui fazer faculdade. Existia alunos infiltrados nas turmas para denunciar os professores. Se trabalhava o patriotismo, porém não adiantava cantar o Hino Nacional e não ter liberdade. Se discutia o tema Ditadura em pequenos grupos, porque ninguém tinha coragem de criticar. Na época da Ditadura tinha muito dinheiro para os municipios. As provas dos alunos vinham prontas. 
Queriam integrar todo o Brasil e os alunos tinham que fazer as provas sem conhecimento. Um professor meu do Magistério foi um preso político e contava histórias sobre a Ditadura brasileira. As pessoas que ocupavam o poder se aliavam aos militares (Aparecida).

Em 1968 o Ato Institucional $n^{\circ} 5$ - AI-5 (BRASIL, 1968) legalizou a censura, proibindo qualquer manifestação. A imprensa, a música e o teatro foram as principais vítimas. A censura passou a esconder a corrupção, a violência policial, as epidemias e inclusive as torturas praticadas pela Ditadura brasileira. A professora Lourdes salienta que não trabalhava temas ligados à Ditadura Civil-Militar na Escola Aníbal Magni.

Era tudo muito imposto, muita lei, vinha de cima para baixo, tinha que engolir. Questionava muito, se fazia a reciclagem de professores. Tinha um treinamento sobre muitas técnicas de inovações em sala de aula no periodo [década de 1980]. Questionei o curso, porque como iria inovar com um livro velho. Depois os livros começaram a vir novos, ter data de validade. Sempre acreditei que as tecnologias iriam melhorar a qualidade das aulas. Fiz um curso de informática. Sempre tive a mente aberta, porque gostava de questionar (Lourdes).

A Ditadura estava presente no cotidiano escolar. Por exemplo, não havia eleição para a escolha do diretor da escola, o processo se dava através da indicação política. Geralmente, o gestor escolar tinha afinidade com os militares que estavam no poder. Sobre a Ditadura Civil-Militar, o professor Rui ressalta que o regime passou despercebido para ele.

Não caiu a ficha que estava trabalhando na época da Ditadura, talvez por trabalhar numa escola do interior. Trabalhei com a disciplina de Educação Moral e Cívica e com a disciplina de OSPB. O lado positivo da Ditadura era a disciplina e os desfiles [marchar, bater tambor e se apresentar em público]. Uma a duas vezes por mês era exigido que se fizesse a hora cívica [poesia, canto, primeiro de tudo se cantava o Hino Nacional]. Pra mim a Ditadura não atingiu [perseguições] (Rui). 
Para muitos professores e alunos, os desfiles de 7 de setembro, data da Proclamação da Independência do Brasil (1822), ficaram marcados nos anos da Ditadura Civil-Militar (1964-1985). De acordo com as memórias, era o momento de marchar, bater tambor e principalmente se apresentar para o público que assistia aos desfiles. A professora Alice destaca que, quando o assunto tratava sobre a Ditadura brasileira, tinha que ter muito cuidado para evitar problemas.

Não podia falar em política, principalmente quando fosse contrário ao regime imposto. Tinha conteúdos nas escolas que eram para ensinar a respeitar e estar na linha dos governos militares. Por outro lado, era mais fácil manter a disciplina nas salas de aula. Tinha atividades de civismo, todos tinham que saber os Hinos e os Símbolos Nacionais. No 7 de setembro tinha que desfilar, caso contrário era suspenso por alguns dias, exceto com atestado médico. Não tinha organização de sindicatos para defender as causas dos trabalhadores de escola. Era tudo imposto, não existia diálogo (Alice).

Em relação às repercussões da Ditadura Civil-Militar brasileira em sala de aula, muitos docentes recordam que na Escola não se falava de política. Outros lembram que as disciplinas de Educação Moral e Cívica (EMC) e Organização Social e Política do Brasil (OSPB) estavam inseridas no currículo escolar e era uma forma de trabalhar com os ideais da Ditadura. Os militares se mantiveram no poder por mais de duas décadas, porque souberam se aliar aos prefeitos e tinham o apoio da elite financeira do país (latifundiários, industriais e banqueiros).

A História Oral se apresentou como um caminho possível para a construção do conhecimento histórico sobre as memórias de docentes da Escola Aníbal Magni durante a Ditadura Civil-Militar (1964-1985). Cabe destacar que as memórias aqui coletadas auxiliam não só ao pesquisador e seu estudo. É o momento do encontro do relator consigo mesmo, com suas recordações. Este reencontro tende a gerar uma sensação de entusiasmo narrativo, um estado de bem-estar pessoal incisivo ora em palavras, em risos, ou até em visões e expressões faciais ao longo da entrevista (BENJAMIN, 1985). 


\section{Considerações finais}

No contexto da consolidação do capitalismo, a agricultura transformouse ao longo dos séculos. No mesmo movimento, elegeram-se as cidades e as atividades comerciais, industriais e financeiras como base dos investimentos sociais, financeiros, culturais e também de conjuntura social. Em outras palavras, num processo apressado de urbanização, evidenciado no Brasil na segunda metade do século XX, as cidades foram alcançando relevo na dimensão inversa da promoção de condições básicas e inevitáveis para o desenvolvimento agrícola e para a sobrevivência dos campesinos no meio rural. Nesta conjuntura, situa-se o ensino rural, e é a partir dele que entendemos a situação precária de funcionamento das escolas rurais no que se refere ao espaço e às condições de trabalho docentes ali estabelecidas.

A memória assume papel decisivo, visto que, além de ser um dispositivo da História, ela é por primazia humana como uma propriedade de preservar certas informações. Utilizar a narrativa como fonte de pesquisa significa preservar aquilo que ainda não se esqueceu, e os conhecimentos dados pelo homem podem ser, por ele mesmo, resgatados e atualizados através de um esforço mental, amparando assim o pesquisador em seu trabalho. Para constituir este estudo, usando a entrevista como estratégica metodológica, ouvimos dez professores. Nesta investigação as histórias possuem nomes, faces, endereços, aflições, personalidades, superações que aparecem desde o fato inesperado de se ter nascido homem ou mulher até as conquistas de um lugar agradável para praticar a profissão escolhida.

Em suas vivências de trabalho são mostradas condições e especificidades do campo e das escolas rurais. Nesses relatos são revelados problemas como pobreza, fome, migração de trabalhadores rurais para as cidades. Essas indagações são representadas no panorama educacional que se executam na falta de escola, precariedade do prédio escolar, se traduzindo em falta de merenda, materiais didáticos, transporte público e baixo salário dos educadores. De outra forma, a proporção mais colaborativa presente nas comunidades rurais é citada pelos docentes, representada pelas celebrações, festividades e relações sociais mais coletivas.

Por fim, as memórias dos docentes da Escola Aníbal Magni promoveram momentos de claridade e novas visões. As memórias permitem uma visibilidade ao cotidiano escolar, seus espaços e tempos, como por exemplo, a relação de amizade que existia entre os docentes e alunos, o apoio da comunidade escolar nas atividades da Escola, a disciplina em sala de aula. Mesmo sendo uma escola 
rural, localizada no norte do Rio Grande do Sul, muitos professores foram perseguidos, como aparece nas narrativas. Por exemplo, eram enviados para outras escolas por causa da questão política e, também, porque não podiam se expressar, temendo alguma retaliação. Dessa maneira, o autoritarismo vigente da Ditadura Civil-Militar se fez presente no pequeno município de Selbach e na comunidade de Arroio Grande.

\section{REFERENCIAS}

ALBERTI, Verena. História dentro da História. In: PINSKY, Carla Bassanezi (org.). Fontes históricas. São Paulo: Contexto, 2005. p. 155-202.

ALMEIDA, Dóris Bittencourt. A educação rural como processo civilizador. In: STEPHANOU, Maria; BASTOS, Maria Helena Camara (org.). Histórias e memórias da educação no Brasil. 3. ed. Petrópolis, RJ: Vozes, 2009a. p. 278-295.

ALMEIDA, Dóris Bittencourt. As memórias e a história da educação: aproximações teórico-metodológicas. História da Educação, Pelotas, v. 13, n. 27, p. 211-243, jan./ abr. 2009b.

AMADO, Janaína. O grande mentiroso: tradição, veracidade e imaginação em História Oral. Revista História, São Paulo, v. 14, p. 125-136, 1995.

ARENDT, Isabel Cristina. Educação, religião e identidade étnica: o Allgemeine Lebrerzeitung e a escola evangélica no Rio Grande do Sul. São Leopoldo: Oikos, 2008.

BARRETO, Elba Siqueira de Sá. Novas políticas educacionais para velhas escolas rurais. Cadernos de Pesquisa, São Paulo, v. 46, p. 23-49, ago. 1983.

BENJAMIN, Walter. O narrador: considerações sobre a obra de Nikolai Leskov. In: BENJAMIN, Walter. Magia e técnica, arte e política: ensaios sobre literatura e história da cultura. 4. ed. São Paulo: Brasiliense, 1985. p. 165-196.

BEZERRA NETO, Luiz. Avanços e retrocessos na educação rural no Brasil. 2003. Tese (Doutorado em Educação) - Universidade Estadual de Campinas, Campinas, 2003.

BOSI, Ecléa. O tempo vivo da memória: ensaios de psicologia social. São Paulo: Ateliê Editorial, 2003.

BRASIL. Presidência da República. Decreto-lei $n^{\circ} 4.958$, de 14 de novembro de 1942. Institue o Fundo Nacional do Ensino Primário e dispõe sobre o Convênio Nacional de Ensino Primário. Rio de Janeiro: Presidência da República, 14 nov. 1942. Disponível em: https://www2.camara.leg.br/legin/fed/declei/1940-1949/decreto-lei-4958-14novembro-1942-414976-publicacaooriginal-1-pe.html. Acesso em: 04 out. 2021. 
BRASIL. Presidência da República. Ato Institucional n. 5, de 13 de dezembro de 1968 . São mantidas a Constituição de 24 de janeiro de 1967 e as Constituições Estaduais; [...]. Brasília, DF, 1968. Disponível em: http://www.planalto.gov.br/ccivil_03/AIT/ait-05-68. htm. Acesso em: 4 out. 2021.

BRASIL. Presidência da República. Lei no 5.692, de 11 de agosto de 1971. Fixa Diretrizes e Bases para o ensino de $1^{\circ}$ e $2^{\circ}$ graus, e dá outras providências. Brasília, DF: Senado, 1971. Disponível em: https://presrepublica.jusbrasil.com.br/legislacao/128525/lei-dediretrizes-e-base-de-1971-lei-5692-71. Acesso em: 4 out. 2021.

CARVALHO, Carlos Henrique; CASTRO, Magali de (org.). Educação rural e do campo. Uberlândia: EDUFU, 2014.

CRESWELL, John W. Projeto de pesquisa: métodos qualitativos, quantitativos e mistos. Tradução de Magda Lopes. 2. ed. Porto Alegre: Artmed, 2007.

DEMARCO, Diogo Joel. Uma análise do Projeto Escola do Campo: Casa Familiar Rural como iniciativa de profissionalização e escolarização de jovens rurais do Estado do Paraná. 2001. Dissertação (Mestrado em Educação) - Universidade de São Paulo, São Paulo, 2001.

DEMARTINI, Zeila de Brito Fabri. A procura da leitura e da escrita na primeira república: recolocando questões. Cadernos do CERU, São Paulo, v. 2, n. 9, p. 57-82, 1998.

ERRANTE, Antoinette. Mas afinal, A Memória é de Quem? Histórias orais e modos de lembrar e contar. História da Educação, Pelotas, v. 4, n. 8, p. 141-174, set. 2000.

FENTRESS, James; WICKHAM, Chris. Memória social: novas perspectivas sobre o passado. Lisboa: Teorema, 1992.

FINGER, Marcos et al. Trabalho de Sociologia: a História do município de Selbach. Sertão: Escola Agrotécnica Federal de Sertão, 1996.

FISCHER, Beatriz Daudt. Foucault e histórias de vida: aproximações e que tais. História da Educação, Pelotas, v. 1, p. 5-20, abr. 1997.

GRAZZIOTIN, Luciane Sgarbi Santos; ALMEIDA, Dóris Bittencourt. Romagem do tempo e recantos da memória: reflexões metodológicas sobre a História Oral. São Leopoldo: Oikos, 2012.

HALBWACHS, Maurice. A Memória Coletiva. Tradução de Beatriz Sidou. São Paulo: Centauro, 2006.

IVASHITA, Simone Burioli; DOMINGUES, Ana Carina Macedo. Memórias da Escola Rural Municipal Amador Bueno: delineamento experiências educativas do norte do Paraná. Pedagog. Foco, Iturama, v. 13, n. 9, p. 21-36, jan./jun. 2018.

JOVCHELOVITCH, Sandra; BAUER, Martin W. Entrevista narrativa. In: BAUER, Martin W.; GASKELL, George (org.). Pesquisa qualitativa com texto, imagem e som: um manual prático. Petrópolis: Vozes, 2002. p. 90-113. 
LE GOFF, Jacques. História e memória. 7. ed. Campinas, SP: Editora Unicamp, 2013. LOURENÇO, Elaine. O ensino de História encontra seu passado: memórias da atuação docente durante a ditadura civil-militar. Revista Brasileira de História, São Paulo, v. 30, n. 60 , p. $97-120,2010$.

LOVISOLO, Hugo. A memória e a formação dos homens. Estudos Históricos, Rio de Janeiro, v. 2, n. 3, p. 16-28, 1989.

MACHADO, Cláudia Aparecida Ferreira. O processo de escolarização na área rural de Montes Claros-MG (1960-1989): memórias e representações de professores e alunos. 2016. Tese (Doutorado em Educação) - Universidade Federal de Uberlândia, Uberlândia, 2016.

MARTINS, Marilda da Conceição. Professoras de escolas rurais: Bolívia, Brasil e México. 2015. Tese (Doutorado em Educação) - Universidade de São Paulo, São Paulo, 2015.

MEIHY, José Carlos Sebe Bom; HOLANDA, Fabíola. História Oral: como fazer, como pensar. 2. ed. São Paulo: Contexto, 2010.

MORAES, Agnes Iara Domingos. Ensino primário tipicamente rural no estado de São Paulo: um estudo sobre as granjas escolares, os grupos escolares e as escolas típicas rurais (1933-1968). 2014. Dissertação (Mestrado em Educação) - Universidade Estadual Paulista, Marília, 2014.

NAGLE, Jorge. Educação e sociedade na Primeira República. São Paulo: EPU; Rio de Janeiro: Fundação Nacional de Material Escolar, 1974.

NEVES, Lucilia de Almeida. Memória, história e sujeito: substrato da identidade. História Oral, São Paulo, v. 3, p. 109-116, 2000.

NORA, Pierre. Entre memória e história: a problemática dos lugares. Tradução de Yara Aun Khoury. Revista Projeto História, São Paulo, v. 10, p. 7-28, dez. 1993.

PESAVENTO, Sandra Jatahy. História \& História Cultural. Belo Horizonte: Autêntica, 2004.

RAMBO, Arthur Blasio. A escola comunitária teuto-brasileira católica. São Leopoldo, Editora Unisinos, 1994.

RIO GRANDE DO SUL. Assembleia Legislativa do Estado. Lei n. 4.762 de 30 de julho de 1964. Altera disposições da Lei no 4.054 de 29 de dezembro de 1960. Porto Alegre: Assembleia Legislativa do Estado, 1964. Disponível em: https://leisestaduais.com.br/ rs/lei-ordinaria-n-4762-1964-rio-grande-do-sul-altera-disposicoes-da-lei-n-4054-de-29de-dezembro-de-1960. Acesso em: 04 out. 2021.

SCHNEIDER, Inque; WENTZ, Neusa Erbes. Um povo e suas histórias. Prefeitura Municipal de Selbach: Secretaria Municipal de Educação, 1992.

SILVEIRA, Tânia Cristina da. A modernidade em Uberlândia e o Ensino Rural. Cadernos de História da Educação, Uberlândia, v. 9, n. 2, p. 543-565, jul./dez. 2010. 
THOMSON, Alistair. Recompondo a memória: questões sobre a relação entre a História Oral e as memórias. Projeto História, São Paulo, v. 15, p. 51-84, abr. 1997.

VEIGA, Cynthia Greive. História da Educação. São Paulo: Ática, 2007.

WEBER, Maria Cristina Backes; HOLZ, Nilsa Maria. A história de Arroio Grande. Tapera: Gráfica Taperense, 1999.

WERLE, Flávia Obino Corrêa. História das Instituições Escolares: responsabilidade do gestor escolar. Cadernos de História da Educação, Uberlândia, v. 3, p. 109-119, jan./ dez. 2004.

WERLE, Flávia Obino Corrêa. Contextos, institucionalização e práticas pedagógicas em escolas normais rurais. In: WERLE, Flávia Obino Corrêa. Educação rural: práticas civilizatórias e instituição da formação de professores. São Leopoldo, Oikos, 2010. p. $87-105$.

Texto recebido em 29/03/2021.

Texto aprovado em 26/07/2021. 